\title{
The Effect of Pomegranate Paste on Neonatal Jaundice Incidence: A Clinical Trial in Women during Pregnancy
}

\author{
Mohsen Manouchehrian1, Mehrdad Shakiba², Mamak Shariat ${ }^{3}$, Mohammad Hassan Lotfi ${ }^{4}$, \\ Mohammad Kamalinejad ${ }^{*}$, Mohammad Babaeian ${ }^{5}$ \\ ${ }^{1}$ Department of Traditional Medicine, Shahid Sadoughi University of Medical Sciences, Ardakan, Iran \\ ${ }^{2}$ Department of Pediatrics, Shahid Sadoughi University of Medical Sciences, Ardakan, Iran \\ ${ }^{3}$ Fetal \& Neonatal Research Center, Tehran University of Medical Sciences, Tehran, Iran \\ ${ }^{4}$ Department of Biostatistics \& Epidemiology, Health Faculty, Shahid Sadoughi University of Medical Sciences, Ardakan, Iran \\ ${ }^{5}$ School of Pharmacy, Shahid Beheshti University of Medical Sciences, Tehran, Iran \\ Email: *mkamalinejad@yahoo.com
}

How to cite this paper: Manouchehrian, M., Shakiba, M., Shariat, M., Lotfi, M.H., Kamalinejad, M. and Babaeian, M. (2017) The Effect of Pomegranate Paste on Neonatal Jaundice Incidence: A Clinical Trial in Women during Pregnancy. International Journal of Clinical Medicine, 8, 144-151. https://doi.org/10.4236/ijcm.2017.83014

Received: January 17, 2017

Accepted: March 26, 2017

Published: March 30, 2017

Copyright $\odot 2017$ by authors and Scientific Research Publishing Inc. This work is licensed under the Creative Commons Attribution International License (CC BY 4.0).

http://creativecommons.org/licenses/by/4.0/

\begin{abstract}
Purpose: Some topics such as women's life style and nutrition and using some special medicines during pregnancy have been discussed and demonstrated as effective factors on infant' health. Based on recommendations in Iranian traditional medicine, we aimed to evaluate the efficacy of pomegranate paste consumed by women during their pregnancy on the neonatal jaundice incidence. Methods: In this single-blinded controlled clinical trial, 80 healthy pregnant women were randomly divided into 2 groups, as treatment and control. The treatment group members added pomegranate paste to their daily diet from the $34^{\text {th }}$ week of the pregnancy to birth, as administered. The levels of neonates' bilirubin were checked in the $5^{\text {th }}$ day of the delivery. Results: Both the need of phototherapy and the mean level of neonates' bilirubin in the group fed with pomegranate paste were significantly lesser compared to control group. The number of neonates who were undergone phototherapy in the pomegranate paste receiving group was significantly lesser than that in the control group $(P$ value $=0.029)$. By measuring the total bilirubin, statically significant difference between the treatment group and the control group was seen $(P$ value $=0.021)$. Conclusion: The results of this study suggest the possible effect of adding pomegranate paste to pregnant women's diet on the incidence of neonatal jaundice.
\end{abstract}

\section{Keywords}

Pomegranate, Hyperbilirubinemia, Neonatal Jaundice, Pregnancy, Iranian Traditional Medicine 


\section{Introduction}

Neonatal jaundice is a common complication in newborns seen in $60 \%$ of term and $80 \%$ of preterm, during the first week of life [1]. It is mostly benign, however, in some cases may turn into catastrophe and needs to be taken seriously. High level of bilirubin for prolonged periods of time could result in permanent brain damage [2].

Although phototherapy is suggested as the first-line treatment of hyperbilirubinemia in neonates, it may put the infant at the risk of important complications such as retinal injury, loose stools, erythematous macular rash, purpuric rash, overheating, dehydration, hypothermia, and a benign condition called bronze baby syndrome [1] [3].

Nowadays, effective prevention of unfavorable and dangerous jaundice requires ongoing vigilance and a practical system-based approach in order to distinguish infants with benign neonatal jaundice from those whose course may be less predictable and potentially harmful [3]. Majority of relevant studies have directed their attention on prevention of jaundice in infants, especially those with risk factors [3] [4].

Although some topics such as women's life style and nutrition and using some special medicines during pregnancy have been discussed and demonstrated as effective factors on infant' healthy [5], to the best of our knowledge, there is no specific, proved or practical recommendation for women during pregnancy to prevent occurrence of jaundice in their newborns.

Various medicinal herbs and traditional medicine remedies have been used for neonatal jaundice for ages globally [6] [7] [8]. Recently, herbal medicines have received a particular attention to discover and develop bilirubin-lowering agents in newborns [8] [9].

According to Iranian traditional medicine references, pomegranate (Punica granatum L.) and its paste possess cold temperament and improve function of liver and biliary tract [10] [11] [12]. It is worth mentioning that in folk medicine of Iran, pomegranate juice has been extracted manually by compressing the arils. Enjoying this method, the astringent constituents such as tannins (responsible for concern to use pomegranate products in pregnancy) are not allowed to enter the juice [12] [13] [14] [15].

In the light of the above mentioned points and since health hazards have not been reported in proper administration of taken routine dosages of pomegranate paste and while it is considered as safe in pregnancy [12] [14] we designed a single-blinded clinical trial to investigate the rate of occurrence of jaundice in newborns whose mothers had consumed pomegranate paste from $34^{\text {th }}$ week of their pregnancy compared to control group.

\section{Materials and Methods}

This single-blind randomized clinical trial was carried out in Lolagar Hospital, Teheran, Iran, from February to August 2015. The performed protocol of the study was approved by the ethical committee on human research of Shahid Sa- 
doughi University of medical sciences, Yazd, Iran. The clinical trial has been registered in Iranian registry of clinical trials (IRCT) database under code: IRCT2015010314760N2.

Eighty nulliparous pregnant women aged between 18 - 35 years were invited to participate in the clinical trial. Pregnant women with any underlying diseases such as diabetes, hypertension, hypothyroidism, and etcetera were excluded from the study. Written informed consent was obtained from all of the participants.

Ripe and sweet pomegranates were purchased from a local store in Kan, Tehran, Iran. The washed fruits were manually peeled and the yielded arils were compressed to extract the juice. The seeds were separated and the filtered juice was conventionally heated and stirred at $90^{\circ} \mathrm{C}$ for 3 hours to achieve proper viscosity and formation the paste [12] [15] [16] [17].

The participants were assigned into two 40-member groups: 1 . the pomegranate paste group (PG) in which the cases were advised to take 1 table spoon of the prepared pomegranate paste, twice a day, before meal from $34^{\text {th }}$ week of the pregnancy until delivery, and 2. the control group (CG) whose members were advised to keep on their routine diet.

The participants were requested to attend our hospital on the $5^{\text {th }}$ day of their childbirth to measure the total serum bilirubin concentration using a Bilitest transcutaneous bilirubin measurement device. The mothers were requested to inform us immediately in the case of witnessing visible icterus before the appointed time. The neonates whose apgar was below 8 , and the neonates whose gestational age was less than 38 weeks, have been excluded.

One-way analysis of variance (ANOVA) and chi-square test were performed to analyze the collected data. $P$ values $<0.05$ were considered statically significant.

\section{Results}

A flow chart for the study is shown in the Figure 1.40 women were allocated to the control group and 40 to the pomegranate paste group. 6 women from CG and 10 from PG were excluded prior to attention scheduled follow-up visit.

There were no statistically significant differences between the two groups with respect to baseline data such as body mass index (BMI), age of subjects, the type of delivery and the neonates' gender and weight (Table 1). The number of neonates whom were undergone phototherapy in the PG was significantly lesser than that in the CG (Figure 2. $P$ value $=0.029$ ). By measuring the total bilirubin, statically significant difference between the PG and the CG was seen (Figure 3, $P$ value $=0.043$ and Figure $4, P$ value $=0.021)$.

\section{Discussion}

In spite of the fact that many researchers have evaluated the effect of herbal remedies on occurred neonatal jaundice, to the best of our knowledge there is not any reported study in which the incidence of jaundice is evaluated in newborns 


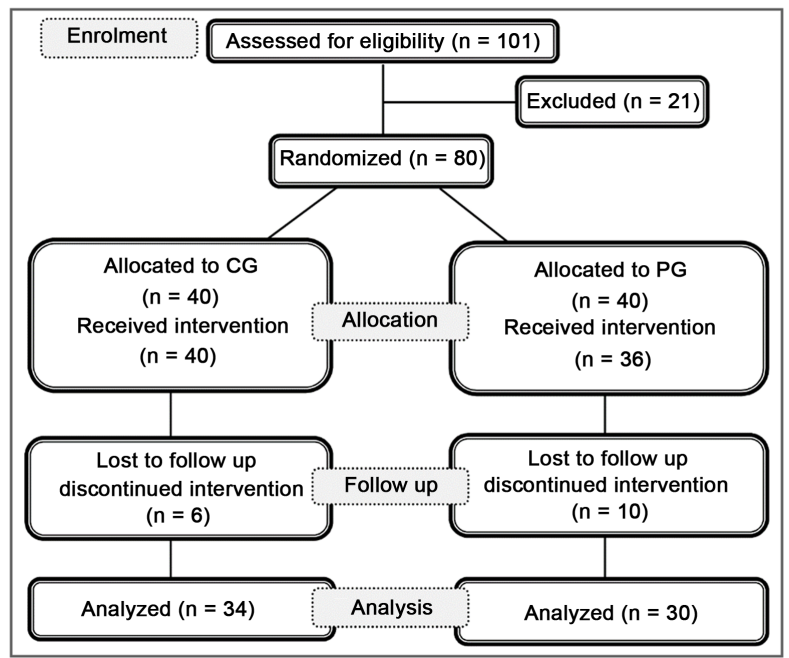

Figure 1. Flow chart of the study.

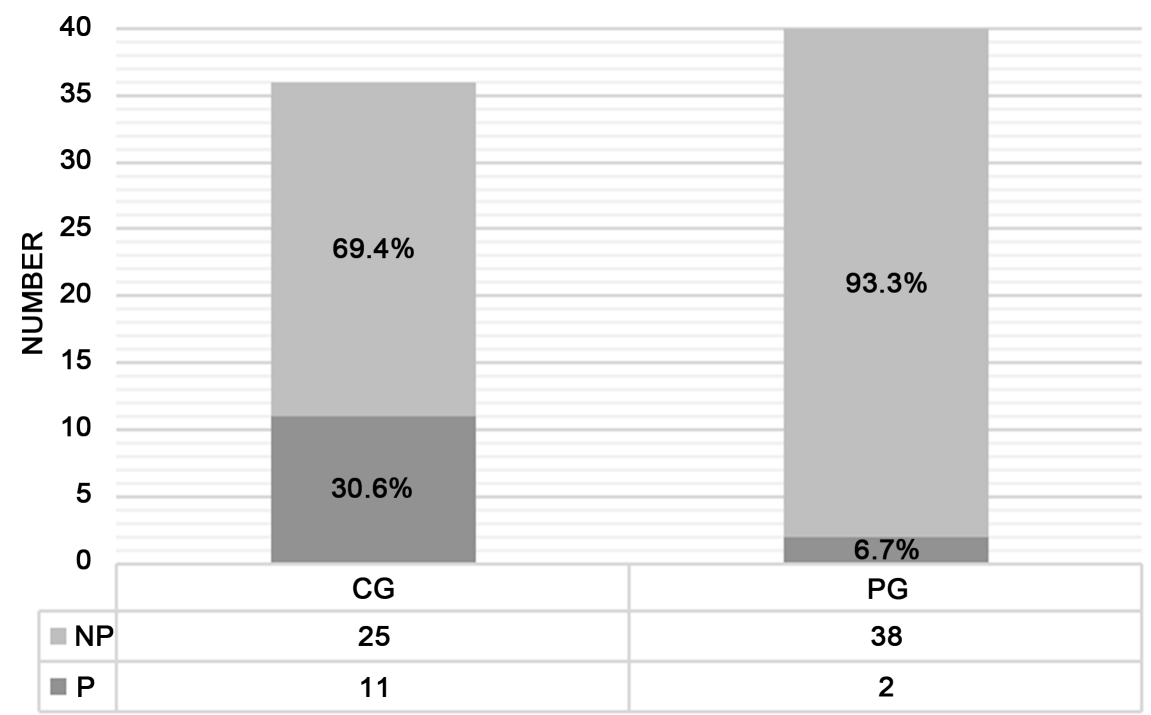

Figure 2. Comparison of the number of the newborns who needed phototherapy ( $\mathrm{P}$ and NP stand for "performed" and "not performed", respectively. $P$ value $=0.029$ ).

Table 1. Distribution of women according to baseline variables ( ${ }^{\circ} \mathrm{Chi}$-square, ${ }^{\star}$ ANOVA).

\begin{tabular}{|c|c|c|c|c|}
\hline \multicolumn{2}{|c|}{ Variables } & CG & PG & $P$ value \\
\hline \multicolumn{2}{|c|}{ Participant's age (years) } & $23.3 \pm 3.6$ & $24.6 \pm 4.6$ & $0.244^{\star}$ \\
\hline \multicolumn{2}{|c|}{ Participant's BMI $\left(\mathrm{kg} / \mathrm{m}^{2}\right)$} & $22.2 \pm 3.9$ & $23.23 \pm 4.8$ & $0.216^{*}$ \\
\hline \multicolumn{2}{|c|}{ Participant's weight gain $(\mathrm{kg})$} & $16.9 \pm 6.6$ & $16.1 \pm 5.8$ & $0.433^{*}$ \\
\hline \multirow[b]{2}{*}{ Type of delivery } & Vaginal & $17(47.2 \%)$ & $7(23.3 \%)$ & \multirow[b]{2}{*}{$0.098^{\bullet}$} \\
\hline & Caesarian & $19(52.8 \%)$ & $23(76.7 \%)$ & \\
\hline \multicolumn{2}{|c|}{ Neonates' weight (gram) } & $3334.7 \pm 348.0$ & $3266.6 \pm 404.5$ & $0.395^{\star}$ \\
\hline & Female & $18(50 \%)$ & $16(53.3 \%)$ & \\
\hline \multirow[t]{2}{*}{ Neonates' gender } & Male & $18(50 \%)$ & $14(46.7 \%)$ & $0.744^{\bullet}$ \\
\hline & Male & $18(50 \%)$ & $14(46.7 \%)$ & \\
\hline
\end{tabular}




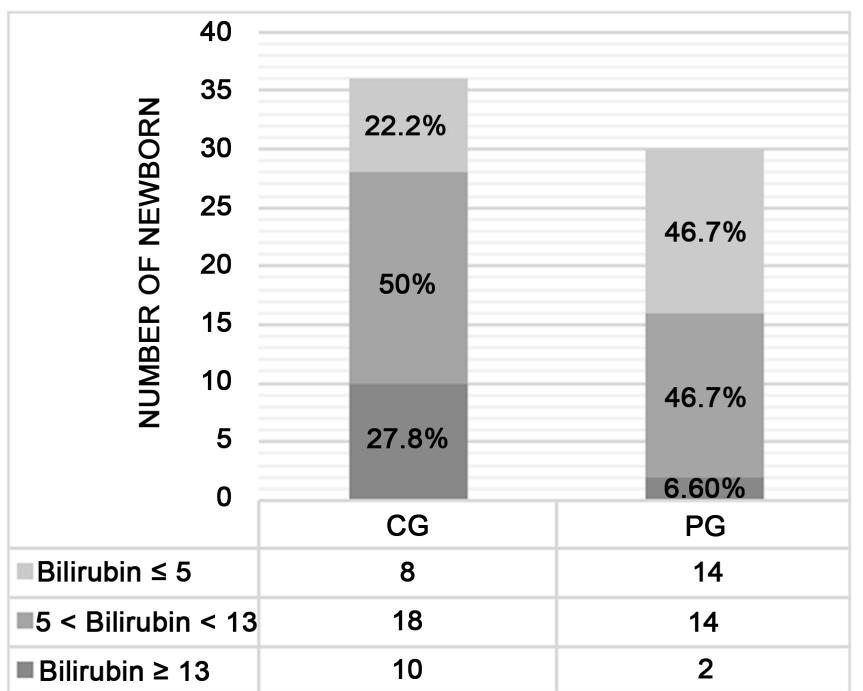

Figure 3. Comparison of the levels of bilirubin in blood samples $(P$ value $=0.043)$.

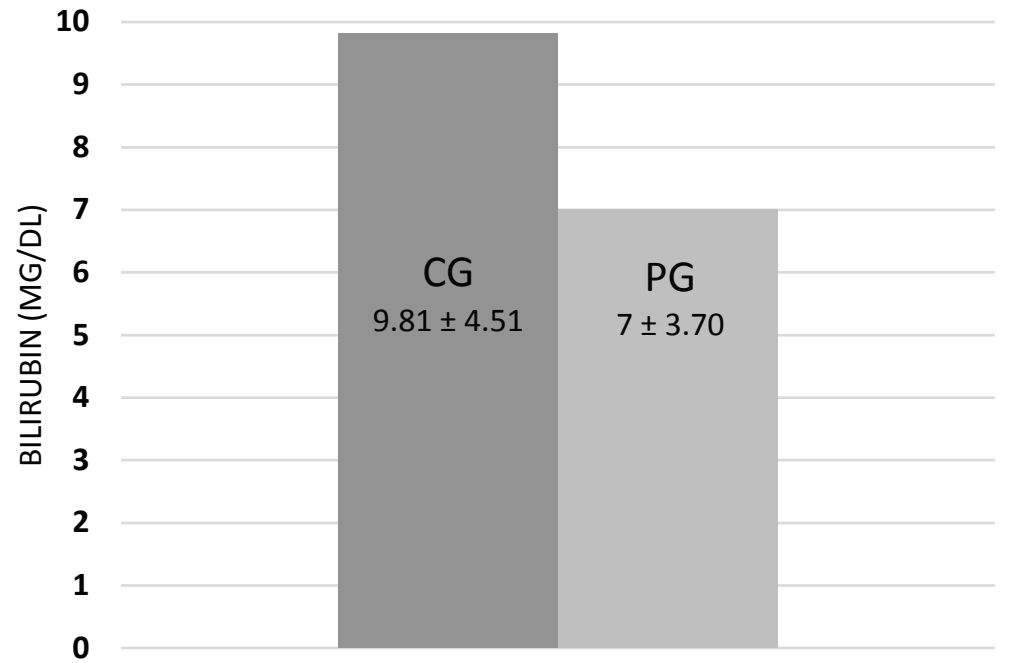

Figure 4. Comparison of the bilirubin level between groups (mean $\pm \mathrm{SD}, P$ value $=$ $0.021)$.

whose mothers took natural products as "prophylactic" during pregnancy. In addition, as far as we know, this is the first randomized comparative trial of the pomegranate paste in the field of jaundice, globally.

Different varieties of pomegranate-the fruit of Punica granatum L. belonging to the family Lythraceae-known as a nutritious fruit in Quran, have been administered in the Iranian traditional medicine to treat hepatic and biliary tract disorders such as jaundice [10] [12] [18]. It has been known and prescribed as tonic to reinforce liver and gastrointestinal tract, to treat jaundice, as hematopoietic in anemia, to treat urinary tract infection, for fatigue feeling, in depression and melancholia and many other complications [10] [12] [15] [19] [20] [21] [22] [23].

Recently, clinical trials have been in progress exploring the beneficial effects of pomegranate's various extracts. Several fields of potential clinical applications of 
pomegranate have been reported in recent years, showing the importance of such natural product in skin care, dental and periodontal conditions, different types of cancer, atherosclerosis, hypertension, diabetes, depression, erectile dysfunction, male infertility, ischemic brain injury, Alzheimer's disease, obesity, inflammation, hyperlipidemia, carotid artery stenosis etcetera [19] [21] [22] [24] [25].

Some researchers and references consider pomegranate arils as safe during pregnancy [12] [14] [26]. On the other hand, the pomegranate seed's astringent polyphenols such as tannins have been reported and known unsafe during pregnancy for their emmenagogue and uterine stimulant effects [13]. This controversy may be due to the difference in the extraction method leading to different chemical composition of the final product. Iranian traditional medicine has advised to use sweet pomegranates' arils (the specialized outgrowth from the seed that completely covers that) for preparing pomegranate various products such as juice and paste and it has been highly recommended to separate the inner seed before processing [10] [12] [18] [27].

In Iranian traditional medicine, jaundice has its roots in liver's excessive warmness [10] [12] [27]. According to Iranian traditional medicine written literature, pomegranate could decrease the blood and liver warmness in pregnant women leading to decline the warmness of their fetus's liver. The decline of fetus liver warmness improves its function, and as a result, incidence of jaundice is reduced [10] [12] [27].

Our findings demonstrated the effectiveness of pomegranate paste for the first time in the incidence of jaundice in newborns whose mothers used it during pregnancy as administered.

Regarding the consumption of pomegranate paste according to the direction by the mother's perfectly, we have no choice but to trust on their own reports.

Further investigations are needed to shed more light on the involved mechanisms of action and to confirm or refute pomegranate paste clinical prophylactic effects on neonatal jaundice.

\section{Acknowledgements}

The authors would like to express their sincere gratitude to the research center of Ardakan's faculty of traditional medicine, Shahid Sadoughi University of Medical Sciences and Lolagar hospital for their support. We must acknowledge Dr. Masih Hashemi Khorasgani, Mr. Majid Ghobadi and Dr. Amir Mohammadkhan for their unfailing help.

\section{Conflict of Interests}

The authors declare that they have not any financial interests.

\section{References}

[1] Stoll, B. and Kliegman, R. (2008) Jaundice and Hyperbilirubinemia in the Newborn. In: Behemen, R., Kliegman, R. and Jenson, H., Eds., Nelson Textbook of Pediatrics, 
18th Edition, Saunders, Philadelphia, 756-765.

[2] Azadbakht, M., Pishva, N., Mohammadi Samani, S. and Alinejad, F. (2005) The Effect of Purgative Manna on the Infant Jaundice. Iranian Journal of Pharmaceutical Sciences, 1, 95-100.

[3] Ambalavanan, N. and Carloa, W.A. (2015) Kernicterus. In: Kliegman, R.M., Stanton, B.F., Schor, N.F. and St Geme, J.W., Eds., Nelson Textbook of Peadiatrics, 20th Edition, Elseviers, New Delhi, 876.

[4] Bhutani, V.K., Poland, R., Meloy, L.D., Hegyi, T., Fanaroff, A.A. and Maisels, M.J. (2016) Clinical Trial of Tin Mesoporphyrin to Prevent Neonatal Hyperbilirubinemia. Journal of Perinatology, 36, 533-539. https://doi.org/10.1038/jp.2016.22

[5] Davies, G.A., Maxwell, C., McLeod, L., et al. (2010) Obesity in Pregnancy. International Journal of Gynecology \& Obstetrics, 110, 167-173. https://doi.org/10.1016/j.ijgo.2010.03.008

[6] Basiri-Moghadam, M., Basiri-Moghadam, K., Kianmehr, M. and Jani, S. (2015) The Effect of Massage on Neonatal Jaundice in Stable Preterm Newborn Infants: A Randomized Controlled Trial. Journal of Pakistan Medical Association, 65, 602-606.

[7] Fok, T.F. (2001) Neonatal Jaundice-Traditional Chinese Medicine Approach. Journal of Perinatology, 21, S98-S100. https://doi.org/10.1038/sj.jp.7210643

[8] Ebrahimimd, S., Ashkani-Esfahani, S. and Poormahmudibs, A. (2011) Investigating the Efficacy of Zizyphus jujuba on Neonatal Jaundice. Iranian Journal of Pediatrics, $21,320-324$

[9] Dennery, P.A. (2002) Pharmacological Interventions for the Treatment of Neonatal Jaundice. Seminars in Neonatology, 7, 111-119. https://doi.org/10.1053/siny.2002.0098

[10] Aghili Khorasani, M.H. (2001) Makhzan-ul-Advieh (Encyclopedia of Ancient medical Drugs). Choogan, Tehran.

[11] Kermani, N.A. (2008) Sharh-ol-Asbab val Alamat. Almoa, Tehran.

[12] Hosseini, M.M. (1979) Tohfeye Hakim Momen. Mahmoudi, Tehran.

[13] Ernst, E. (2002) Herbal Medicinal Products during Pregnancy: Are They Safe? BJOG, 109, 227-235. https://doi.org/10.1111/j.1471-0528.2002.t01-1-01009.x

[14] Montvale, J., Brendler, T. and Jaenicke, C. (2000) PDR for Herbal Medicines. Medical Economics Company, Montvale.

[15] Mousavinejad, G., Emam-Djomeh, Z., Rezaei, K. and Khodaparast, M.H.H. (2009) Identification and Quantification of Phenolic Compounds and Their Effects on Antioxidant Activity in Pomegranate Juices of Eight Iranian Cultivars. Food Chemistry, 115, 1274-1278. https://doi.org/10.1016/j.foodchem.2009.01.044

[16] Muzaffar, K., Dinkarrao, B.V. and Kumar, P. (2016) Optimization of Spray Drying Conditions for Production of Quality Pomegranate Juice Powder. Cogent Food \& Agriculture, 2, Article ID: 1127583. https://doi.org/10.1080/23311932.2015.1127583

[17] Yildiz, H., Bozkurt, H. and Icier, F. (2009) Ohmic and Conventional Heating of Pomegranate Juice: Effects on Rheology, Color, and Total Phenolics. Food Science and Technology International, 15, 503-512. https://doi.org/10.1177/1082013209350352

[18] Tabatabaei, M.H. (1996) Almizan Fi Tafsir Al-Quran. Translated by Mussavi, M.B., The Office of Qum Hawze Ilmieh Teachers' Society, Vol. 16, 313-415.

[19] Miguel, M.G., Neves, M.A. and Antunes, M.D. (2010) Pomegranate (Punica granatum L.): A Medicinal Plant with Myriad Biological Properties-A Short Review. Journal of Medicinal Plants Research, 4, 2836-2847. 
[20] Dabaghian, F.H., Kamalinejad, M., Shojaei, A. and Fard, M.A. (2012) Presenting Anti-Diabetic Plants in Iranian Traditional Medicine. Journal of Diabetes and Endocrinology, 3, 70-76. https://doi.org/10.5897/JDE12.004

[21] Tavakkoli-Kakhki, M., Motavasselian, M., Mosaddegh, M., et al. (2014) Omega-3 and Omega-6 Content of Medicinal Foods for Depressed Patients: Implications from the Iranian Traditional Medicine. Avicenna Journal of Phytomedicine, 4, 225-230.

[22] Dastjerdi, E.V., Abdolazimi, Z., Ghazanfarian, M., Amdjadi, P., Kamalinejad, M. and Mahboubi, A. (2014) Effect of Punica granatum L. Flower Water Extract on Five Common Oral Bacteria and Bacterial Biofilm Formation on Orthodontic Wire. Iranian Journal of Public Health, 43, 1688-1694.

[23] Kamali, M., Khodadoost, M., Tavakoli, H., et al. (2016) The Role of Syndrome Differentiation in the Clinical Efficacy of Punica granatum on Patients with Ulcerative Colitis. Iranian Journal of Medical Sciences, 41, S15.

[24] Pantuck, A.J., Leppert, J.T., Zomorodian, N., et al. (2006) Phase II Study of Pomegranate Juice for Men with Rising Prostate-Specific Antigen Following Surgery or Radiation for Prostate Cancer. Clinical Cancer Research, 12, 4018-4026. https://doi.org/10.1158/1078-0432.CCR-05-2290

[25] Jurenka, J. (2008) Therapeutic Applications of Pomegranate (Punica granatum L.): A Review. Alternative Medicine Review, 13, 128-144.

[26] Chen, B., Longtine, M.S. and Nelson, D.M. (2013) Punicalagin, a Polyphenol in Pomegranate Juice, Downregulates p53 and Attenuates Hypoxia-Induced Apoptosis in Cultured Human Placental Syncytiotrophoblasts. American Journal of Physiology-Endocrinology and Metabolism, 305, E1274-E1280. https://doi.org/10.1152/ajpendo.00218.2013

[27] Aghili Khorasani, M.H. (2008) Kholastol Hekmat. RICM, Qom.

Submit or recommend next manuscript to SCIRP and we will provide best service for you:

Accepting pre-submission inquiries through Email, Facebook, LinkedIn, Twitter, etc. A wide selection of journals (inclusive of 9 subjects, more than 200 journals)

Providing 24-hour high-quality service

User-friendly online submission system

Fair and swift peer-review system

Efficient typesetting and proofreading procedure

Display of the result of downloads and visits, as well as the number of cited articles

Maximum dissemination of your research work

Submit your manuscript at: http://papersubmission.scirp.org/

Or contact ijcm@scirp.org 